\title{
Determination of Glycol Ethers in Ambient Air by Adsorption Sampling and Thermal Desorption with GC/MS Analysis: Performance Evaluation and Field Application
}

\author{
YOUNG-KYO SEO and SUNG-OK BAEK* \\ Department of Environmental Engineering, \\ Yeungnam University, Gyeongsan-si, Republic of Korea - 712-749 \\ sobaek@yu.ac.kr
}

Received 5 November 2011; Accepted 25 December 2011

\begin{abstract}
Some of glycol ethers, such as 2-methoxyethanol (2-ME) and 2-ethoxyethanol (2-EE) are known to be toxic and classified as hazardous air pollutants in USA, Japan and Germany. In Korea, however, there has been no study conducted so far for these compounds in ambient air. In addition, no clear methodologies for the measurement of glycol ethers have been yet established. We carried out this study to evaluate a sampling and analytical method for the determination of glycol ethers, in ambient air samples collected in specific industrial areas of South Korea. To measure glycol ethers, adsorption sampling and thermal desorption with GC/MS analysis were used in this study. The analytical method showed good repeatability, linearity and sensitivity. The lower detection limits were estimated to be approximately $0.3 \sim 0.5 \mathrm{ppb}$. Based on storage tests, it was suggested that samples should be analyzed within two weeks. It was also demonstrated that this method can be used for the simultaneous measurement of glycol ethers and other aromatic VOCs such as benzene, toluene, and xylenes. Field sampling campaign was carried out at 2 sites, located in a large industrial area, from October 2006 to June 2007, and a total of 480 samples were collected seasonally. Among them, 2-ME was not detected from any samples, while 2-EE and 2-Ethyloxyethylacetate (2EEA) were found in 7 and 70 samples, respectively. The measured concentrations of 2-EE and 2-EEA for samples were ranged from 0.7-2.5 $\mathrm{ppb}$ and from $0.5-10.5 \mathrm{ppb}$, respectively. To our knowledge, this is the first measurement report for glycol ethers in the ambient atmosphere not only in Korea but also the rest of the world.
\end{abstract}

Keywords: Glycol ethers, 2-Methoxyethanol, 2-Ethoxyethanol, 2-Ethoxyethylacetate, Volatile organic compounds (VOCs), GC/MS, Hazardous air pollutants(HAPs). 


\section{Introduction}

2-Methoxyethanol (2-ME) and 2-ethoxyethanol (2-EE) are classified as glycol ethers and have been included in the list of 187 hazardous air pollutants (HAPs) regulated by the U.S. Clean Air $\mathrm{Act}^{1}$. In addition, they have both been classified as specific HAPs in Japan, and 2-EE has been stated as a HAP in Germany ${ }^{2}$ also. However, 2-ethoxyethylacetate (2-EEA) is not governed by any regulations as a HAP, even in developed countries. In Korea, these three compounds have not yet been under regulation, but included in the list of 48 priority air pollutants by the Ministry of Environment ${ }^{3}$.

Glycol ethers, including 2-ME, 2-EE and 2-butoxyethanol (2-BE), are widely used as solvents in the manufacture of lacquers, varnishes, resins and printing inks owing to their excellent hydrophilic and lipophilic properties ${ }^{4-7}$. 2-ME is mass-produced in industrial complexes for use as a jet fuel deicer in the USA, but its demand has decreased since 1980. The exposure to glycol ethers in the environment is usually via the air. 2-ME in water or soil is partially volatilized into the air and is removed by wet deposition by its reaction with hydroxyl radicals. Although the general level of 2-ME in ambient air does not directly cause adverse effects on the environment, it was reported that 2-ME as one of the contributors to photochemical smog due to its reaction with volatile organic compounds. It was reported that most of these were emitted via the air. The public are exposed to these chemicals via consumer goods, such as a washing agent, liquid soap and cosmetics, while workers' exposure is via chemicals in the workplace . $^{8}$

Acute exposure to high levels of glycol ethers in humans results in narcosis, pulmonary edema, and severe liver and kidney damage. Chronic exposure to glycol ethers in humans may result in neurological and blood effects, including fatigue, nausea, tremors and anemia ${ }^{9}$. The emission rates in Korea for 2-ME was estimated as $8,880 \mathrm{~kg} / \mathrm{y}$ in 2006 and 8,950 kg/y in 2007 while for 2 -EE it is $84,442 \mathrm{~kg} / \mathrm{y}$ in 2006 and $55,816 \mathrm{~kg} / \mathrm{y}$ in $2007^{10}$. Glycol ethers are taken into humans via breathing, skin contact and polluted water or foods and removed from the body through urine and breathing ${ }^{11}$. The bio-indicator for the exposure of 2-ME is 2-methoxy acetic acid in the urine.

The analytical methodology for exposure to 2-ME, 2-EE and 2-BE in a workplace are described in National Institute of Occupational Safety and Health (NIOSH) Method $1403^{12}$. $1 \mathrm{~L}$ to $50 \mathrm{~L}$ of the air sample is carried out using a solid adsorbent, such as of coconut shell charcoal and analyzed using GC/FID after their ultrasonic extraction using dichloromethane /methanol (95:5). The detection limits for 2-ME and 2-EE were reported as 800 and $700 \mathrm{ng}$, respectively. Occupational Safety and Health Administration (OSHA) suggests Method 53 and 79 for the analysis of high and low levels of glycol ethers, respectively ${ }^{13,14}$. Method 79 is the same as NIOSH Method 1403. KOSHA A-1-030 of the Korea Occupational Safety \& Health Agency also follows a similar analytical procedure as suggested above, with the exception of the extraction solvent $\left(\mathrm{CS}_{2}\right.$ including $5 \%$ methanol); this method detection limits are at the high level of $0.01 \sim 0.02 \mathrm{mg}^{15}$.

Shih et al. used a coconut shell charcoal tube as a sampling medium in an occupational environment, and analyzed the samples using GC/FID after dichloromethane/methanol (95:5) solvent extraction for $40 \mathrm{~min}^{9}$. The overall accuracy was $\pm 9.5 \%$, with a detection limit of $4 \mathrm{ng}$. They applied this method for 27 workers from a semiconductor factory for the manufacture of copper circuits, and the $8 \mathrm{~h}$ weighted average concentration of 2-ME was $4.46 \mathrm{ppm}( \pm 2.56 \mathrm{ppm})$ in the general workplace and $81.61 \mathrm{ppm}( \pm 111.7 \mathrm{ppm})$ in a special operation workplace. In particular, a high level of 2-ME was shown in the procedure of mixing feed stocks and washing a coating machine.

Methods of HPLC with pre-column derivatizations have been used for the analysis of alkoxyethanols by several authors ${ }^{16-18}$. Solvent extraction was conducted using acetonitrile 
with dichloromethane (1:9) for samples collected by charcoal tubes, with the analysis then carried out by the HPLC (Fluorescence) after derivatization by the addition of $0.5 \%$ quinuclidine and $0.1 \% 1$-anthroylnitrile. The detection limit for this method has been reported as low as 1 3 pg. The material used for the derivatization in their study was 1- anthroylnitrile ${ }^{19}$. Yoshikawa and $\mathrm{Tani}^{4}$ collected air samples from occupational environments where 2-EE, 2BE, 2-butanol, methyl isobutyl ketone and ethyl acetate were used. They found the concentrations of 2-EE and 2-BE in air were 150 and $8 \mathrm{ppb}$, respectively.

As shown above, most of the studies on glycol ethers, such as 2-ME and 2-EE, have only been carried out in a limited part of occupational environments. Thus far, there has been no study conducted in ambient air, to which the general public is routinely exposed. In addition, no clear methodologies have yet been established for the measurement of glycol ethers at very low levels in non-occupational environments.

In this study, we evaluated the feasibility of the measurement of glycol ethers in ambient air and focusing on simultaneous measurement with other VOCs, such as benzene, toluene, and xylenes. Glycol ethers including 2-ME, 2-EE and 2-EEA were determined by adsorption sampling followed by thermal desorption and GC/MS analysis, which is one of the standard methods for the measurement of airborne $\mathrm{VOCs}^{20}$. The performance of the method was evaluated by a laboratory study, and then field application was carried out seasonally from October 2006 to June 2007 in the Sihwa/Banwall industrial complex, which is one of the largest industrial areas in Korea.

\section{Experimental}

2-ME, 2-EE and 2-EEA were selected as the target analytes, with 3-methyl-1-pentene -3-ol (3MP) used as an internal standard for GC analysis. Table 1 shows the physical properties of the target compounds. Samples were collected using double sorbent traps filled in a stainless steel tube $(0.64 \mathrm{~cm}$ diameter by $9 \mathrm{~cm}$ length, Perkin Elmer, UK) in the order of increasing adsorbance. The front part of a tube was packed with $100 \mathrm{mg}$ of Carbotrap C adsorbent (20/40 mesh, Supelco Inc., USA) and the back part was packed with $400 \mathrm{mg}$ of Carbotrap adsorbent (60/80 mesh, Supelco Inc., USA). Before using, all the adsorbent tubes were cleaned with an automatic pretreatment machine (TC-20, Thermal Conditioner, Markers Inc., UK) in the flow of helium, $80 \mathrm{~mL} / \mathrm{min}$ for $1 \mathrm{~h}$ in $250{ }^{\circ} \mathrm{C}$, for $1 \mathrm{~h}$ in $300^{\circ} \mathrm{C}$ and for $30 \mathrm{~min}$ in $350{ }^{\circ} \mathrm{C}$.

Table 1. Physicochemical properties of target glycol ethers.

\begin{tabular}{cccc}
\hline Compounds & 2-Methoxyethanol & 2-Ethoxyethanol & 2-Ethoxyethylacetate \\
\hline CAS No. & $109-86-4$ & $110-80-5$ & $111-15-9$ \\
Abbreviation & $2-\mathrm{ME}$ & $2-\mathrm{EE}$ & 2 -EEA \\
Molecular Weight & 76.09 & 90.1 & 132.16 \\
Appearance & Colorless liquid & Colorless liquid & Colorless liquid \\
Boiling Point & $124^{\circ} \mathrm{C}$ & $135{ }^{\circ} \mathrm{C}(275 \mathrm{mmHg})$ & $156.4^{\circ} \mathrm{C}$ \\
Molecular Formula & $\mathrm{C}_{3} \mathrm{H}_{8} \mathrm{O}_{2}$ & $\mathrm{C}_{4} \mathrm{H}_{10} \mathrm{O}_{2}$ & $\mathrm{C}_{6} \mathrm{H}_{12} \mathrm{O}_{3}$ \\
Usage & Resins, paints & Resins, brightener & Solvent \\
Symptoms & Irritation eyes, & Irritation eyes, lung & Irritation eyes, paralysis \\
headache & damage & \\
Molecular & $>$ & \langle &
\end{tabular}


After the cleaning process, all adsorbent tubes were firstly sealed using a 1/4" Swagelok stainless steel cap and poly tetrafluoroethylene ferrule, and then sealed in $50 \mathrm{~mL}$ glass vials with a septum. Samples were collected by a STS 25 (Sequential tube sampler 25, Perkin Elmer, UK) and FLEC Air pump 1001 (Field and Laboratory Emission Cell, Chematec, Denmark) at a flow rate of $50 \mathrm{~mL} / \mathrm{min}$ for $4 \mathrm{~h}$. The flow rates were measured in the field using an Ultraflow Electronic Calibrator (SKC Inc., USA), and determined as the average of at least 3 replicates before and after sampling. The variation of flow rates was regarded as insignificant because the relative standard deviation (RSD) was within $2 \%$.

\section{Analytical method}

Standard materials were produced at 4 levels, 30, 60, 150 and $300 \mathrm{ng} / \mu \mathrm{L}$ using stock materials (2-ME 99.8\%, 2-EE 99\%, 2-EEA 98\% and 3MP 99\%, Sigma-Aldrich, USA) diluted with methanol. Standard materials were spiked on an adsorbent tube through a GC packed column injector. The temperature of the injector was $300{ }^{\circ} \mathrm{C}$, with helium used as the carrier gas at a flow rate of $120 \mathrm{~mL} / \mathrm{min}$. After $1 \mu \mathrm{L}$ of spiking, the adsorption tube was separated from the GC packed column injector after about $30 \mathrm{sec}$. Analysis was carried out using an automatic thermal desorption (ULTRA/UNITY, Markes, UK) coupled to a GC column (Rtx-1, $0.32 \mathrm{~mm}$ $\times 105 \mathrm{~m} \times 1.5 \mu \mathrm{m})$ of a GC/MS (HP 6890/5973, USA) system. The thermal desorption of an adsorbent tube was initially conducted for $10 \mathrm{~min}\left(300^{\circ} \mathrm{C}, 50 \mathrm{~mL} / \mathrm{min}\right)$, with the temperature then rapid increased from -15 to $320{ }^{\circ} \mathrm{C}$ for injection into the $\mathrm{GC}$. The detailed operating conditions of the UNITY/ULTRA and GC/MS are shown in Table 2. Typical GC/MS chromatograms for standard sample and field sample are shown in Figure 1.

Table 2. Operating conditions of thermal desorption and GC/MS analysis.

\begin{tabular}{|c|c|c|c|}
\hline \multicolumn{2}{|c|}{ UNITY/ULTRA (Markes, UK) } & \multicolumn{2}{|c|}{ GC/MSD (HP6890/5973, Hewlett Packard, USA) } \\
\hline Oven temp. & $300^{\circ} \mathrm{C}$ & GC column & Rtx-1 (0.32 mm $105 \mathrm{~m}, 1.5 \mu \mathrm{m})$ \\
\hline Desorb time and flow & $10 \mathrm{~min}, 50$ & Initial temp. & $50^{\circ} \mathrm{C}(10 \mathrm{~min})$ \\
\hline Cold trap holding time & $5 \mathrm{~min}$ & Oven ramp rate & $5^{\circ} \mathrm{C} / \mathrm{min}$ \\
\hline Cold trap high temp. & $320^{\circ} \mathrm{C}$ & Final temp. & $250^{\circ} \mathrm{C}(10 \mathrm{~min})$ \\
\hline Cold trap low temp. & $-15^{\circ} \mathrm{C}$ & Column flow & $1.4 \mathrm{~mL} / \mathrm{min}$ \\
\hline Cold trap packing & $\begin{array}{c}\text { Tenax } \\
\text { TA/Carbonack } \mathrm{B}\end{array}$ & Detector type & Quadruple \\
\hline Min. pressure & 15 psi & Q-pole temp. & $150^{\circ} \mathrm{C}$ \\
\hline Inlet split & No & $\begin{array}{l}\text { MS source } \\
\text { temn }\end{array}$ & $230^{\circ} \mathrm{C}$ \\
\hline Outlet split & $14 \mathrm{~mL} / \mathrm{min}$ & Mass range & $35 \sim 300 \mathrm{amu}$ \\
\hline Valve and line temp. & $200{ }^{\circ} \mathrm{C}$ & $\begin{array}{l}\text { Electron } \\
\text { energy }\end{array}$ & $70 \mathrm{eV}$ \\
\hline
\end{tabular}

\section{Field application}

Field samples were collected from two sites: one in the Sihwa industrial complex and the other in the Banwall industrial complex. The Sihwa/Banwall complex is located near to the capital Seoul metropolitan area with a large number of industrial, mobile and community based sources of pollution. The sampling sites were all located in the center of each industrial complex, where the traffic volume was relatively low. Thus, the VOC contribution from traffic sources was regarded as negligible. The sampling was simultaneously carried out in two sites from October 2006 to June 2007 for 10 consecutive days per season (January, April, June and October). Sampling duration for each sample was $4 \mathrm{~h}$, and 6 samples per day were collected by a STS25 automatic sampler. As a result, a total of 480 samples were collected at two sites. Details of sampling period are given in Table 3. 

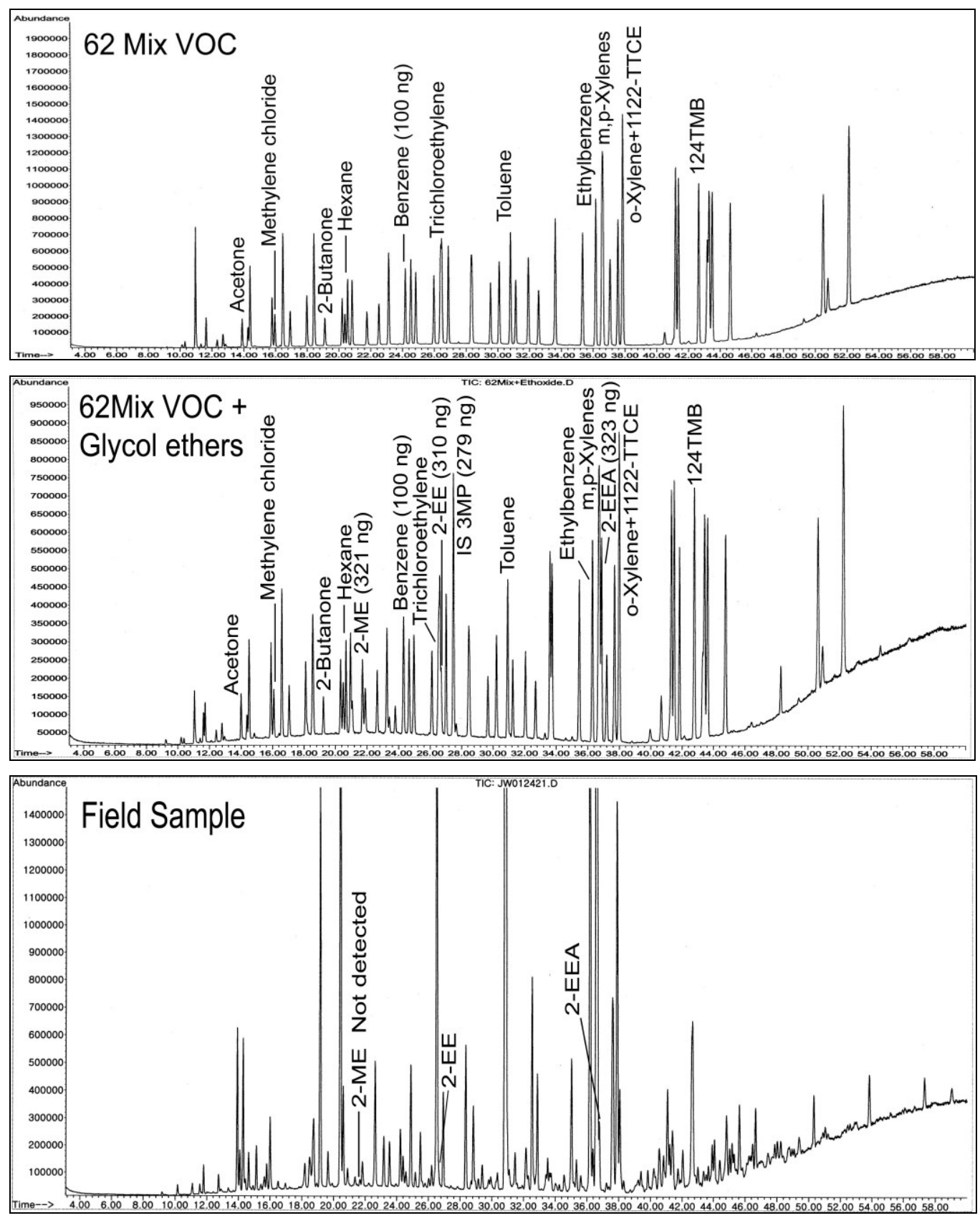

Figure 1. Typical GC/MS chromatograms for standard and field samples.

Table 3. Sampling periods and weather conditions.

\begin{tabular}{ccc}
\hline Season & Sampling periods(YY/MM/DD) & Weather conditions \\
\hline Fall & $2006.10 .21 \sim 2006.10 .30$ & average temperature: $7 \sim 19^{\circ} \mathrm{C}$ \\
Winter & $2007.1 .20 \sim 2007.1 .29$ & average temperature: $-6 \sim 5{ }^{\circ} \mathrm{C}$ \\
Spring & $2007.4 .21 \sim 2007.4 .30$ & average temperature: $10.5 \sim 15.4^{\circ} \mathrm{C}$ \\
Summer & $2007.6 .17 \sim 2007.6 .26$ & average temperature: $17.6 \sim 31.3^{\circ} \mathrm{C}$ \\
\hline
\end{tabular}




\section{Results and Discussion}

\section{Repeatability and linearity}

The repeatability was evaluated by using the RSD to the response factor of standard samples. In general, it has been reported that the repeatability of the response factor within $30 \%$ is satisfactory ${ }^{17}$. In addition; the repeatability of the peak area was evaluated from the consecutive analysis of the same amount, $279 \mathrm{ng}$, of the internal standard(3MP). Table 4 shows the results of the repeatability for a standard sample and the internal standard, which indicated repeatability lower than about 25.8 and $42.6 \%$ for the target materials and the internal standard, respectively and less than $0.1 \%$ for the retention time. From the results, it was regarded that $3 \mathrm{MP}$ was not required as an internal standard in the analysis of glycol ethers by GC/MSD. Deuterated benzene or toluene could also be used as internal standards. Figure 2 shows the linearity of GC/MSD analysis of a wide range of standard samples; 30, 60, 150 and $300 \mathrm{ng} / \mu \mathrm{L}$. The $\mathrm{R}^{2}$ for all target materials were over 0.96 .

Table 4. The repeatability of the standard samples and internal standard.

\begin{tabular}{cccc}
\hline No & Compound & $\begin{array}{c}\mathrm{RSD}^{\mathrm{a}} \text { of Response Factor or } \\
\text { Area }(\mathrm{n}=11)\end{array}$ & $\begin{array}{c}\text { RSD of Retention } \\
\text { Time }(\mathrm{n}=14)\end{array}$ \\
\hline Standard & 2-Methoxyethanol & $22.6 \%^{\mathrm{b}}$ & $0.08 \%$ \\
Standard & 2-Ethoxyethanol & $25.8 \%^{\mathrm{b}}$ & $0.06 \%$ \\
Standard & 2-Ethoxyethylacetate & $15.0 \%{ }^{\mathrm{b}}$ & $0.09 \%$ \\
Internal & 3-methyl-1-pentene-3-ol & $22.6 \%{ }^{\mathrm{c}}$ & $0.09 \%$ \\
Standard & & & \\
\hline
\end{tabular}

${ }^{a} R S D($ relative standard deviation $)=S D /$ Mean $\times 100 ;{ }^{b}$ RSD of Response Factor; ${ }^{c} R S D$ of Area.

\section{Lower detection limits}

The lower detection limits (LDL) were evaluated from the instrumental detection limit (IDL) and the method detection limit (MDL). The IDL were calculated using the ratio of the signal to noise from the GC chromatogram in the level area, the 2.5. MDL was evaluated for 8 samples were spiked into adsorbent tubes with 2-ME (32.1 ng), 2-EE (31.0 ng) and 2-EEA (32.3 ng). Table 5 shows the results obtained for the MDL and IDL as weight (ng) and volume (ppb), which were lower $0.7 \mathrm{ppb}$ in ambient concentrations for all target compounds.

Table 5. Estimation of the method detection limits for glycol ethers.

\begin{tabular}{ccc}
\hline Compound & MDL $^{\mathrm{a}}$ in mass & MDL in concentration \\
\hline 2-Methoxyethanol & $21.1 \mathrm{ng}$ & $0.56 \mathrm{ppb}^{\mathrm{b}}$ \\
2-Ethoxyethanol & $15.9 \mathrm{ng}$ & $0.35 \mathrm{ppb}$ \\
2-Ethoxyethylacetate & $20.1 \mathrm{ng}$ & $0.31 \mathrm{ppb}$ \\
\hline
\end{tabular}

${ }^{a} M D L:$ Method Detection Limit, $M D L=S D \times t(n-1,0.01)$, where $n=8$ in this study. ${ }^{b}$ detection limit in concentration units was estimated on the assumption a $12 \mathrm{~L}$ air sample. 

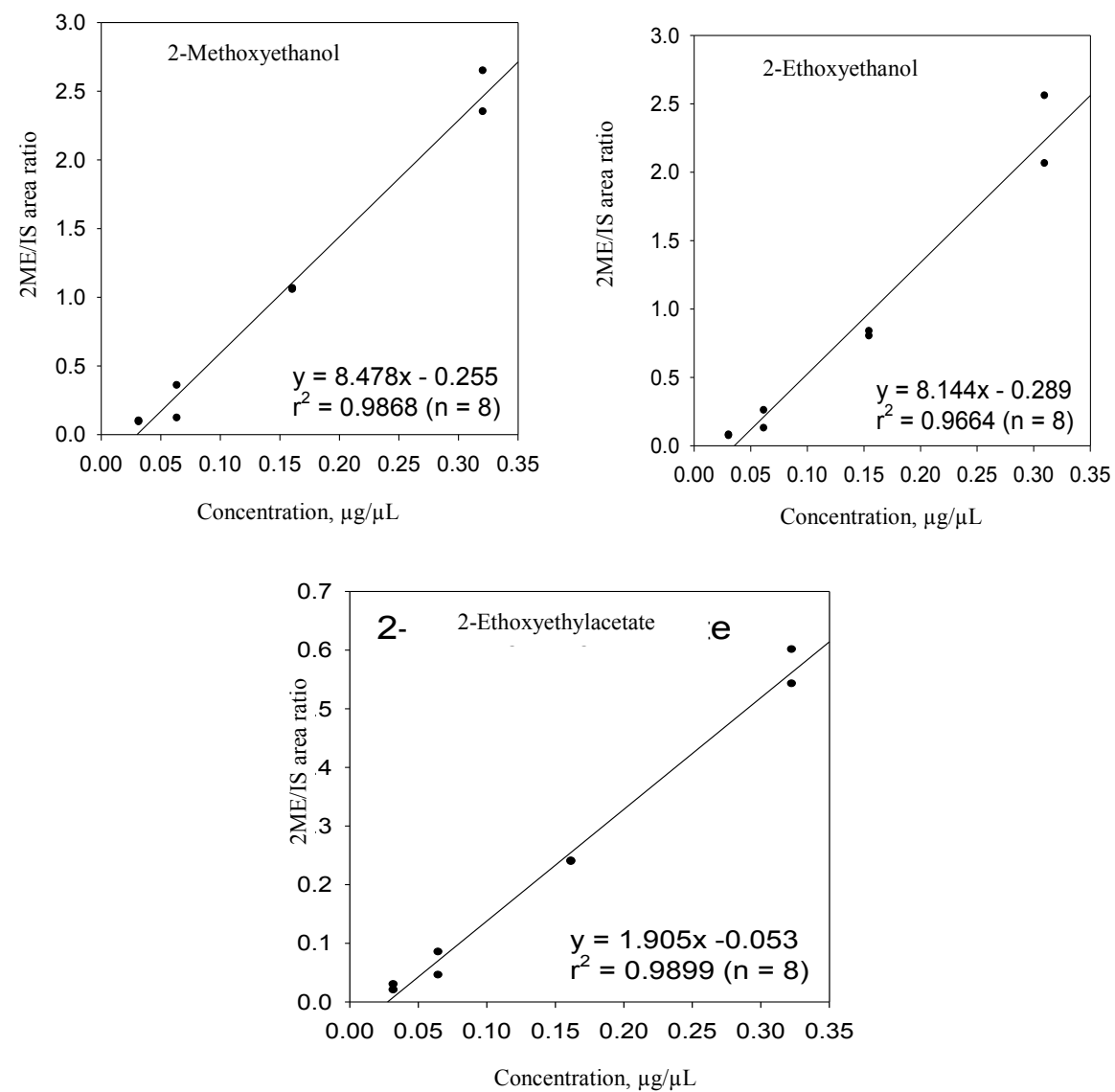

Figure 2. Linearity of the GC/MS analysis for standard samples at different levels.

\section{Storage test}

About 300 ng of each the target materials was spiked into an adsorbent tube for a storage test on the samples. 2 out of 12 tubes were analyzed on the day, with the other 10 stored at $2 \sim 4{ }^{\circ} \mathrm{C}$. A further 2 tubes were analyzed at 2 day intervals after $2,4,8,16$ and 32 days. The variations in the concentrations of target compounds were calculated, with the amount of adsorbent compensated for using the internal standard materials and compared to those with no compensation. Figure 3 shows the decrease in the amount of adsorbent on the glycol ethers after 16 days of storage. In addition, the decrease was more significant in the samples in which no internal standard materials compensation was conducted. The average variation ratio in the amount of adsorbent up to 16 days storage was about 0.9. Accordingly, samples of glycol ethers should be analyzed within 2 weeks of sampling.

\section{Application for field monitoring}

As shown in Table 6, 2-EEA was detected at both Jungwang2dong and Wonsidong, but 2-EE was only detected at Wonsidong. However, 2-ME was detected at neither area. 2-EE was detected in only 7 of the 480 samples (detection frequency $1.4 \%$ ) and only detected at Wonsidong during January (4 samples), April (2 samples) and June (1 sample). 

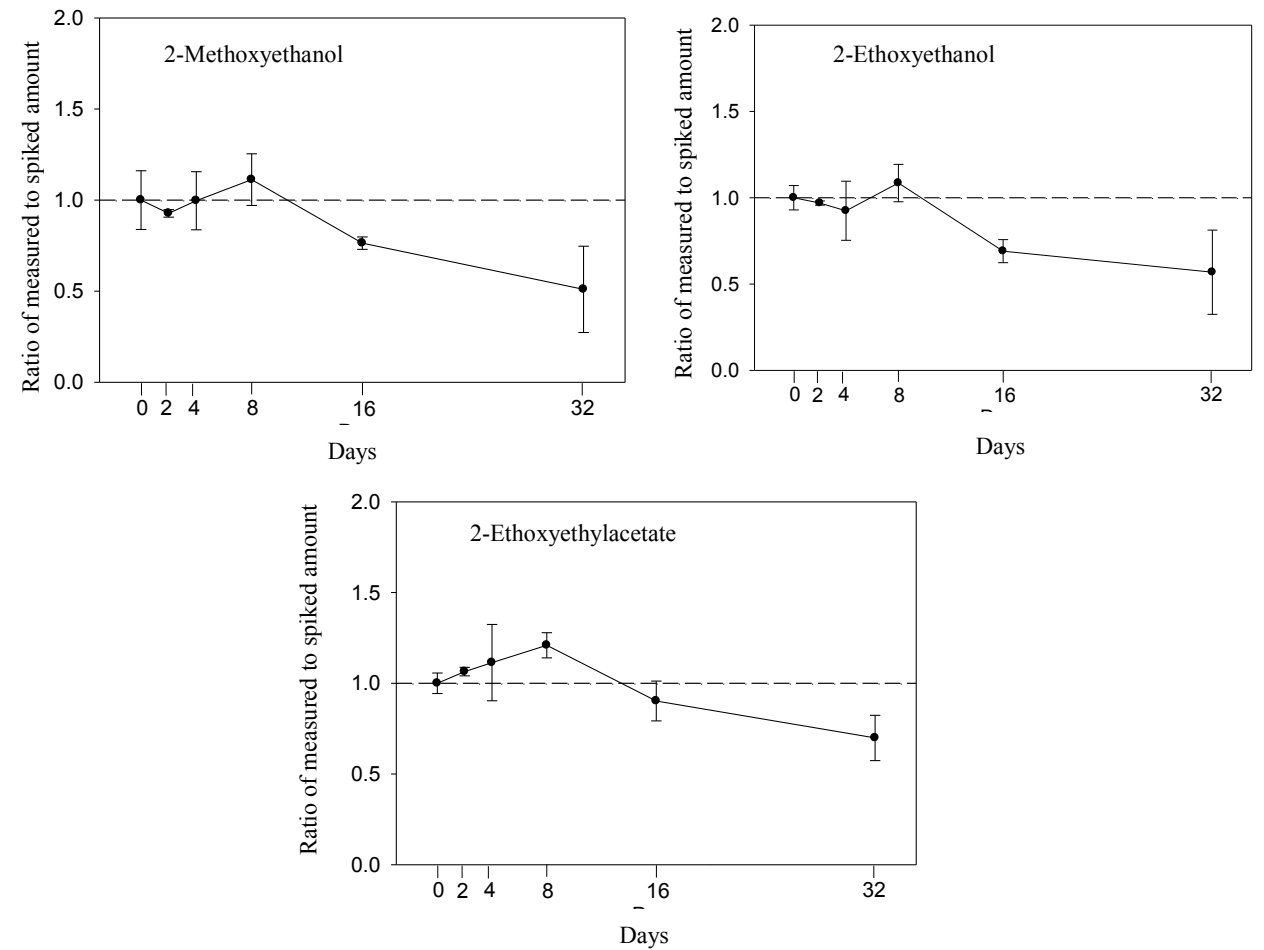

Figure 3. Results of storage tests for standard samples.

Table 6. Detection frequencies and concentrations of glycol ethers at the industrial areas.

\begin{tabular}{cccc}
\hline Fall & Winter & Spring & Summer \\
$(2006$. Oct $)$ & $(2007$. Jan $)$ & $(2007$. Apr $)$ & $(2007$. Jun $)$ \\
\hline
\end{tabular}

Site Target
D. F. ${ }^{a} \operatorname{Min} \sim \operatorname{Max}^{b}$
D. F. Min Max
D. F. Min Max
D. F. Min Max

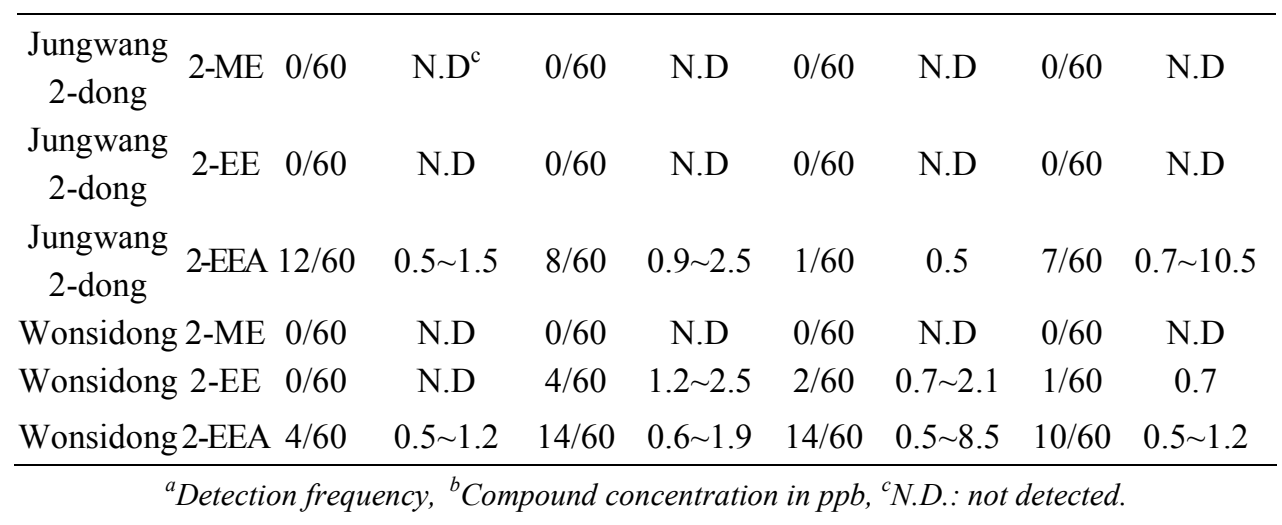


The maximum and minimum concentrations of 2-EE were found as 2.5 and $0.7 \mathrm{ppb}$, respectively. 2-EE was mostly detected from 13:00 to 21:00. The mean concentrations were 1.63, 1.39 and $0.67 \mathrm{ppb}$ in January, April and June, respectively, which were much lower than the $150 \mathrm{ppb}$ limit for an occupational environment reported by Yoshikawa and Tani. ${ }^{4}$ Therefore, the concentration of 2-EE was not at a level of concern, since its concentration and detection frequency at the industrial complexes were low. 2-EEA was detected in 70 of the 480 samples (detection frequency 14.6\%) and evenly throughout the year at both of Jungwang2dong and Wonsidong. The maximum and minimum concentrations were 10.5 and $0.5 \mathrm{ppb}$, respectively. Although there were some difficulties in the seasonal comparison due to the relatively high concentrations at Wonsidong (April) and Jungwang2dong (June), the concentration of 2-EEA was highest in the order: June (2.19 $\pm 2.91 \mathrm{ppb})$, April (1.33 $\pm 2.01 \mathrm{ppb})$, January $(1.11 \pm 0.54 \mathrm{ppb})$ and October $(0.81 \pm 0.25 \mathrm{ppb})$. The concentrations of VOCs measured with the glycol ethers are shown in Table 7. The seasonal mean concentrations of benzene and toluene were $0.44 \sim 1.39 \mathrm{ppb}$ and 7.27 26.24 ppb, respectively, the highest concentrations were observed in January, 2007.

Table 7. Mean concentrations of VOCs at the industrial areas.

\begin{tabular}{lcccccccccc}
\hline \multirow{3}{*}{ Compound } & \multicolumn{4}{c}{ Jungwang2dong $^{\mathrm{a}}$} & \multicolumn{4}{c}{ Wonsidong $^{\mathrm{a}}$} \\
\cline { 2 - 11 } & $\begin{array}{c}2006.10 \\
(\mathrm{n}=60)\end{array}$ & $\begin{array}{c}2007.1 \\
(\mathrm{n}=60)\end{array}$ & $\begin{array}{c}2007.4 \\
(\mathrm{n}=60)\end{array}$ & $\begin{array}{c}2007.6 \\
(\mathrm{n}=58)\end{array}$ & $\begin{array}{c}\text { Total } \\
(\mathrm{n}=238)\end{array}$ & $\begin{array}{c}2006.10 \\
(\mathrm{n}=60)\end{array}$ & $\begin{array}{c}2007.1 \\
(\mathrm{n}=60)\end{array}$ & $\begin{array}{c}2007.4 \\
(\mathrm{n}=60)\end{array}$ & $\begin{array}{c}2007.6 \\
(\mathrm{n}=58)\end{array}$ & $\begin{array}{c}\text { Total } \\
(\mathrm{n}=238)\end{array}$ \\
\hline Benzene & 0.77 & 1.39 & 1.00 & 0.44 & 0.90 & 0.71 & 1.17 & 0.61 & 0.49 & 0.75 \\
Toluene & 18.41 & 26.24 & 14.20 & 7.27 & 16.61 & 18.47 & 21.31 & 12.06 & 15.66 & 16.88 \\
Ethylbenzene & 2.49 & 3.51 & 1.79 & 1.89 & 2.42 & 2.02 & 2.51 & 1.46 & 1.79 & 1.95 \\
m,p-Xylenes & 5.14 & 6.24 & 3.81 & 3.08 & 4.58 & 4.50 & 5.00 & 2.62 & 2.65 & 3.69 \\
Styrene & 0.38 & 0.54 & 0.12 & 0.36 & 0.35 & 0.26 & 0.45 & 0.18 & 0.21 & 0.28 \\
$o$-Xylene & 1.67 & 1.83 & 1.05 & 0.87 & 1.36 & 1.46 & 1.50 & 0.77 & 0.79 & 1.13 \\
\hline
\end{tabular}

${ }^{a}$ Compound concentration in ppb, ${ }^{b} n=$ number of samples.

\section{Conclusion}

A feasibility study on the reliable measurement of glycol ethers (2-ME, 2-EE and 2-EEA) in ambient air was carried out. In the study, the general measurement method for VOCs, adsorbent-thermal desorption-GC, was used to analyze the glycol ethers. Samples were collected using an adsorbent tube filled with Carbotrap and Carbotrap $\mathrm{C}$ at a flow rate of 50 $\mathrm{mL} / \mathrm{min}$ for $4 \mathrm{~h}$. The analysis was carried out using a GC/MSD coupled with automatic thermal desorption. In the QA and QC, the linearities of the detections of 2-ME, 2-EE and 2-EEA were over 0.96 with respect to the $\mathrm{R}^{2}$ values, with repeatability (RSD) in the response factors lower than about $26 \%$. The estimated LDL was lower, at $0.7 \mathrm{ppb}$, than the ambient concentration level. In the storage test, the amount of adsorbent was significantly decreased after 16 days of storage, with an average variation ratio in the amount of adsorbent after up to 16 days of storage of about 0.9 . Thus, field samples should be analyzed within 2 weeks of sampling. All 480 field samples in ambient air were seasonally collected at Sihwa and Banwall industrial complexes (Jungwang2dong and Wonsidong) from October 2006 to June 2007. From the results, no 2-ME was detected, and the detection frequencies of 2-EE and 2-EEA were 1.4 and $14.6 \%$, respectively. The concentrations of 2-EE and 2-EEA were $0.7 \sim 2.5$ and $0.5 \sim 10.5 \mathrm{ppb}$, respectively.

From the QA, QC and field sampling, it was concluded that the typical measurement method for VOCs, adsorbent-thermal desorption-GC, could be used to simultaneously measure glycol ethers and VOCs in ambient air. In addition, the concentrations of 2-ME and 2-EE were at 
levels below those that would be causes for concern, since their concentrations and detection frequencies at the industrial complexes were both low. To our knowledge, this is the first measurement of glycol ethers in the ambient atmosphere not only in Korea but also in the rest of the world.

\section{Acknowledgment}

This research was supported by the Yeungnam University research grants in 2007.

\section{References}

1. US EPA: Modification to the section 112(b) 1 (Clean air act amendments), Hazardous air pollutants, 2005.

2. Wiederkehr P, In Managing Hazardous Air Pollutants; Chow W and Connor K K, Ed., Lewis Publishers, Boca Raton, U.S.A. 1993, 29.

3. Ministry of Environment, Republic of Korea. http://www.me.go.kr

4. Yoshikawa M and Tani C, J Chromatogr A., 2003, 1005, 215.

5. Hildenbrand S, Gfrörer W, Schmahl F W and Dartsch P C, Arch Toxicol., 2000, 74, 72.

6. Wilkinson S C and Faith M W, Toxicol., 2000, 148, 37.

7. U.S. EPA, Technology transfer network, air toxics website, glycol ethers, http:// www.epa.gov/ttn/atw/hlthef/glycolet.html.

8. U.S. EPA, Chemicals in the environment: 2-methoxyethanol, EPA 749-F-94-019, http://www.epa.gov/chemfact/f_methox.txt.

9. Shih T S, Liou S H, Chen C Y and Chou J S, Occup Environ Med., 1999, 56, 674.

10. National Chemicals Information System, http://ncis.nier.go.kr.

11. Gunnar J, Crit Rev in Toxicol., 2000, 30, 307.

12. NIOSH Method 1403, http://www.cdc.gov/niosh/nmam/pdfs/1403.pdf.

13. OSHA Method 53, http://www.osha.gov/dts/sltc/methods/organic/org053/org053.html.

14. OSHA Method 79, http://www.osha.gov/dts/sltc/methods/organic/org079/org079. html.

15. KOSHA Method A-1-030, http://www.kosha.or.kr.

16. Haj-Yehia A I and Benet L Z, J Chromatogr A, 1996, 724, 107.

17. Katayama M, Masuda Y and Taniguchi H, J Chromatogr A, 1991, 585, 219.

18. Iwata T, Yamaguchi M, Hara S and Nakamura M, J Chromatogr A, 1986, 362, 209.

19. Goto J, Goto N, Shamsa F, Saito M, Komatsu S, Suzaki K and Nambara T, Anal Chim Acta, 1983, 147, 397.

20. U.S. EPA, Compendium of methods TO-17. Determination of toxic organic compounds in ambient air, 2 ${ }^{\text {nd }}$ Ed., EPA/625/R-96/010b, 1997. 


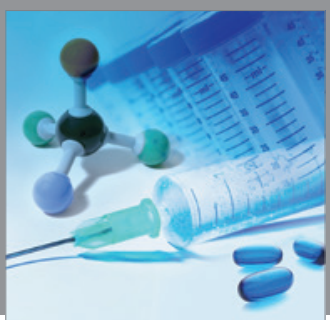

International Journal of

Medicinal Chemistry

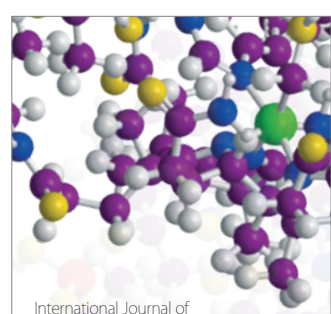

Carbohydrate Chemistry

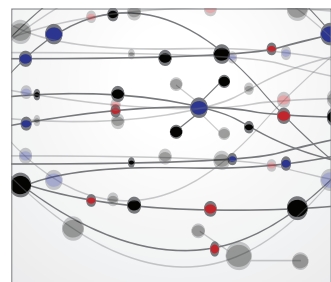

The Scientific World Journal
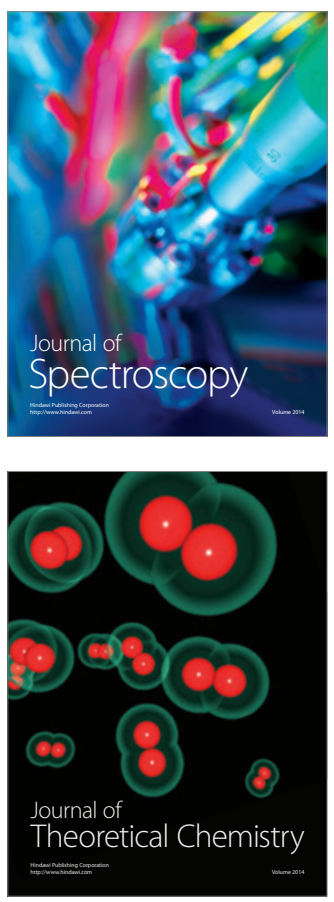
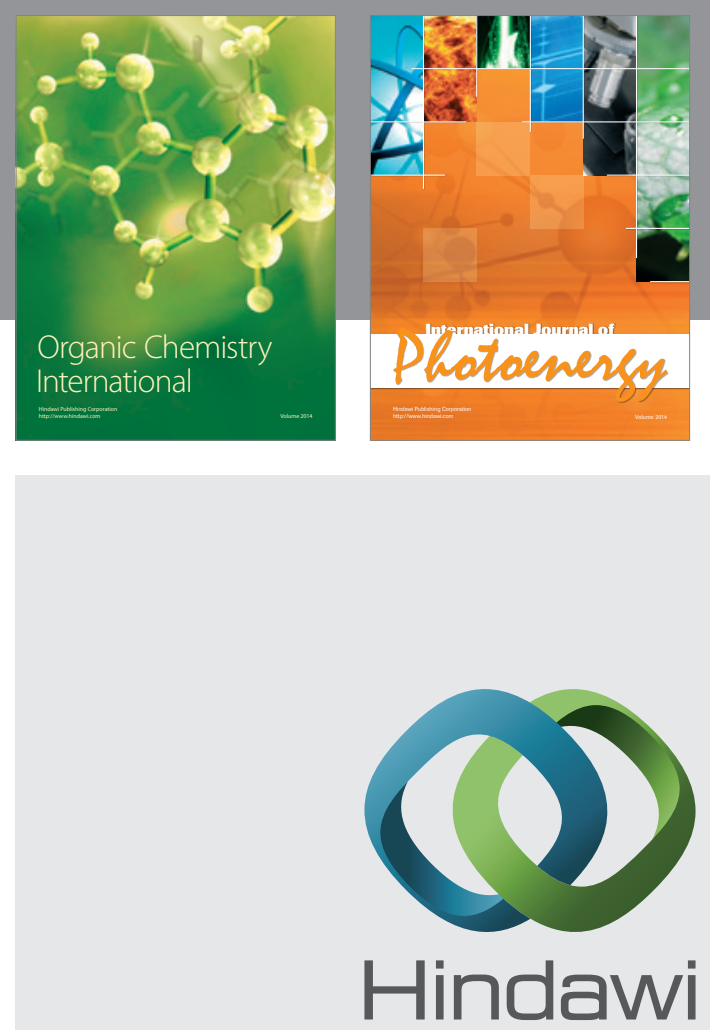

Submit your manuscripts at

http://www.hindawi.com
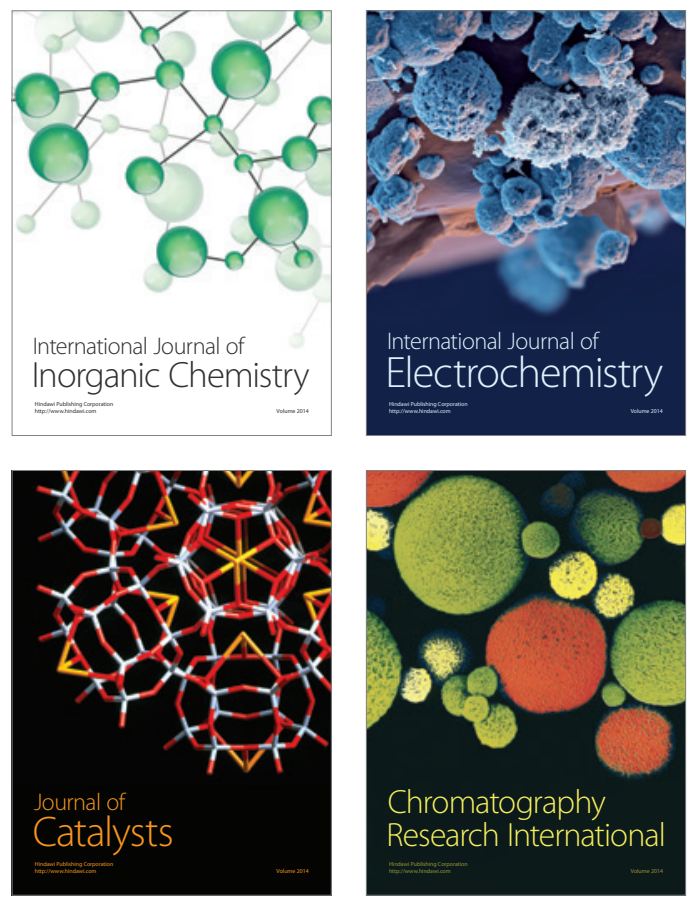
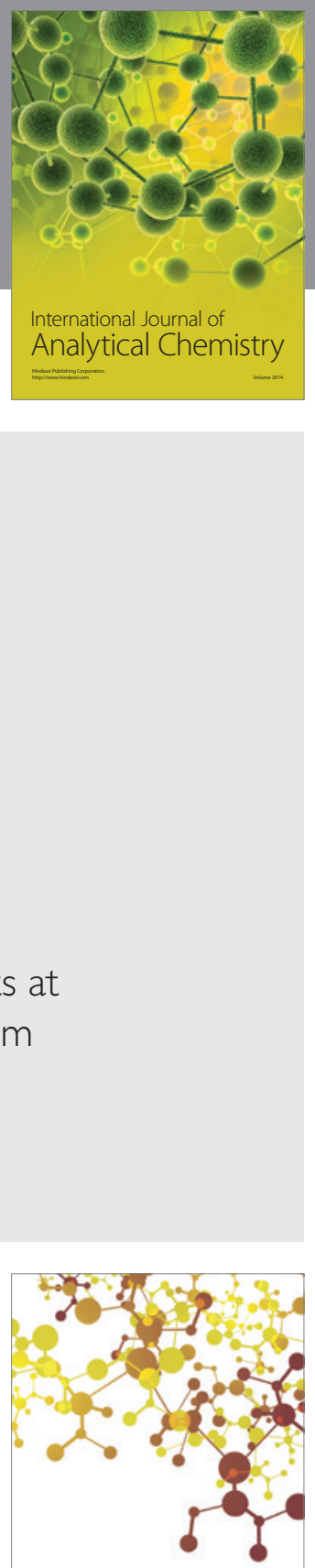

Journal of

Applied Chemistry
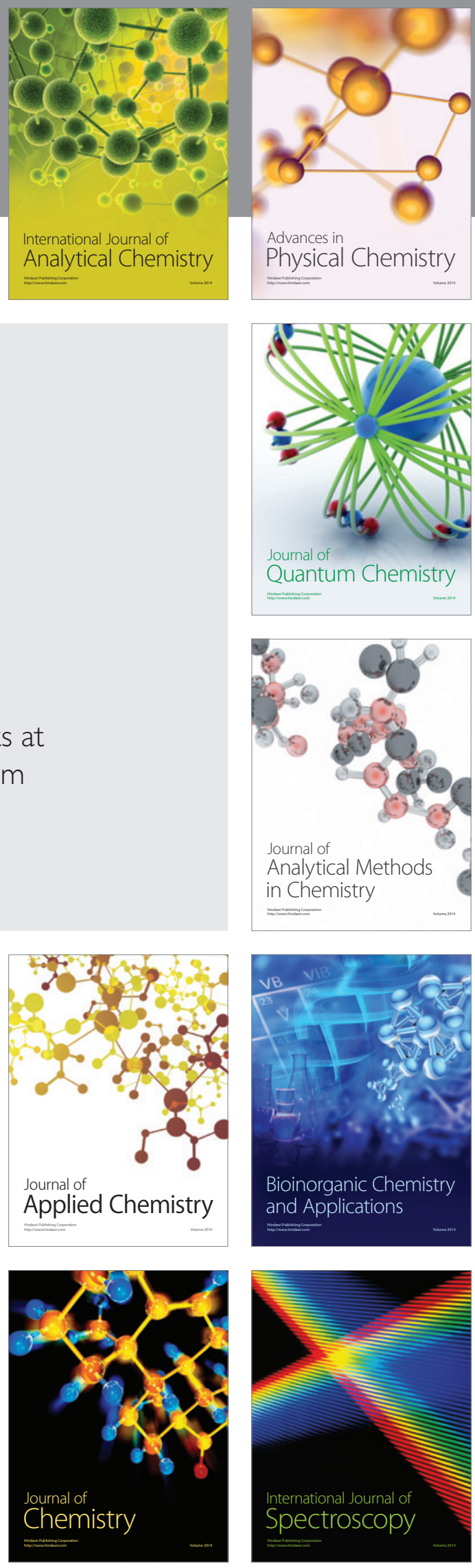